\title{
Virtual Screening of Potential Drug Molecules Against Covid-19 Targets: A Drug Repurposing Approach
}

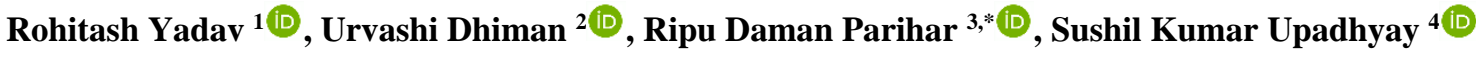 \\ 1 Department of Pharmacology, All Indian Institute of Medical Sciences, Rishikesh-249203, India; \\ rohitashyadav1@gmail.com (R.Y.); \\ 2 Department of Zoology, DAV University, Jalandhar -144012, Punjab, India; dhiman17urvashi@ gmail.com (U.D.); \\ 3 Department of Zoology, University of Jammu, Jammu-180006, Jammu \& Kashmir, India; ripuparihar89@gmail.com \\ (R.D.P.); \\ 4 Department of Biotechnology, Maharishi Markandeshwar (Deemed to be University), Mullana-Ambala-133207 \\ (Haryana), India; upadhyay.k.sushil@gmail.com (S.K.U.); \\ * Correspondence ripuparihar89@gmail.com (R.D.P.);
}

Scopus Author ID 56692536400

Received: 19.04.2021; Revised: 28.05.2021; Accepted: 6.06.2021; Published: 27.06.2021

Abstract: Severe acute respiratory syndrome coronavirus 2 (SARS-CoV-2) has shattered normal life across the world. This deadly virus displays many variants and has claimed many lives in various countries. Spike protein plays a major role in the transmission and infectivity of this virus. The scientific community is trying hard to reign this virus and save human lives. In this effort, drug repurposing has emerged as a reliable tool to screen FDA-approved drugs. In the present study, we did a virtual screening of 265 FDA-approved drugs against two important covid-19 targets (Non-structural protein \& main protease) with PDB IDs 6W4H, 6LU7, and 6W63. A comparative analysis of the best drugs based on docking score, binding energy, and effective hits was done against both targets. Out of 265 molecules, the best 7 molecules showed reliable hits against both targets. Best seven drugs namely Saquinavir, Indinavir, Tenofovir Alafenamide, Ritonavir, Nelfinavir mesylate, Cefiderocol and Plazomicin. Our results suggest that these ligands, in combination or individually, can be taken as novel prospects for developing a drug against SARS CoV-2.

Keywords: SARS-CoV-2; non - structural protein; main protease; FDA drugs; molecular docking. Abbreviations: CoV: Coronavirus, MERS: Middle East Respiratory Syndrome, SARS: Sudden Acute Respiratory Syndrome, MD: Molecular dynamics, COVID - 19: Coronavirus Disease 2019, RNARibonucleic acid, PDB: Protein Data Bank, HTVS: High throughput virtual screening, FDA- Food and drug administration WHO: World Health Organization, NSP: Non-Structural Proteins, 3CP: 3' Chemotrypsin-like protease.

(C) 2021 by the authors. This article is an open-access article distributed under the terms and conditions of the Creative Commons Attribution (CC BY) license (https://creativecommons.org/licenses/by/4.0/).

\section{Introduction}

SARS-CoV-2 possess single-stranded RNA in a spherical or pleomorphic shape with club-shaped glycoproteins on their enveloped outer surface [1]. The SARS-CoV-2 directly affects the respiratory tract, leading to a similar disease to Acute Respiratory Distress Syndrome (ARDS) associated with labored breathing, commonly known as COVID-19 [2]. The World Health Organization (WHO) has declared this outbreak as a pandemic that is affecting the entire world [3]. 
The previous study on bats has revealed that this novel virus shares $89.1 \%$ nucleotide similarity of $89.1 \%$ SARS-CoV and [4]. It has twelve putative (ORF) open reading frames, which encode both structural and non-structural proteins $[5,6]$

There are mainly four structural proteins in CoV-2, i.e., the trimeric spike of $\mathrm{S}$ glycoprotein having S1 and S2 subunits responsible for attachment, fusion, and entry, matrix protein (M protein), an envelope protein (E protein), and nucleocapsid protein ( $\mathrm{N}$ protein) for RNA synthesis of virus and replication along with some proteases[1,7,8]. The SARS CoV-2 has papain-like and 3-Chymotrypsin-like proteases (3CP), that belong to the cysteine protease family, while HIV protease belongs to the aspartic protease family. The 3CP, such as $6 \mathrm{~W} 63$ and 6LU7, cleaves $\mathrm{C}$-terminus at 11 sites of polyproteins undergoing replication. They recognize a specific core sequence [ILMVF]-Q-|-[SGACN] and bind with an AD-ribose-1"phosphate (ADRP) as well. While non-structural proteins like NSP10 stimulates NSP14 3'-5' exoribonuclease and NSP16 2'-O-methyltransferase activities methylation of mRNAs cap via formation NSP10/NSP16 hetero-oligomeric complexes with 2'-O-ribose methyltransferase (NSP 16) to evade the immune system of the host [9]. Due to a lack of detailed knowledge regarding the activity of SARS-CoV-2, the scientific community is exploring drugs with an interdisciplinary approach and without the box ideas.

The WHO proposed several targets for drug development and repurposing of existing approved drugs [10]. Among the first is to attack the virus with monoclonal antibodies or plasma obtained from the recovered patients. The second is to inhibit the ACE2. The third is the inhibition of viral endocytosis by using antimalarial drugs. Fourth is the inhibition of general or specific proteases, which causes proteolysis of polypeptides by anti-HIV, anti-HCV, and other antiretroviral drugs. And the fifth is to inhibit RNA polymerization and viral replication.

The international status of the coronavirus- 2 treatment is still in a quagmire in the want of evidence-based confirmed therapy. However, many expedient treatments have been tried, such as existing drugs to treat HIV, Other Coronaviruses, antimalarial drugs, and other drugs used for infectious diseases [11]. Therefore, WHO has launched big clinical trials with promising therapies such as plasma and antibody treatment, earlier anti-CoV drugs such as remdesivir, chloroquine, hydroxychloroquine used for malaria, and other Anti-HIV drugs like lopinavir/ritonavir combinations [12]. In addition, anti-inflammatory drugs baricitinib and thalidomide have been proposed to limit cytokine surge in COVID-19 patients based on their previous clinical reports. While other anti-inflammatory drugs, like tocilizumab (Anti-TNF $\alpha$ antibody), have been used in trials in China and Italy for their decreasing cytokine storm capabilities $[13,14]$.

The results of using convalescent plasma of the recovered patients are very promising, and therefore, it is being used as a treatment in many countries, including China and the US $[15,16]$. The scientists believed that the IL-6 cytokine might be responsible for causing the cytokine storm. Thus blocking its effect will reduce the severity of illness. One such monoclonal antibody which has been developed to reduce its effects in rheumatoid arthritis is tocilizumab. So its administration in COVID-19 patients in China concluded that it might be an effective therapy to reduce its severity. Another case report from a Chinese university has proved that thalidomide, an immunomodulatory drug, may have an adjuvant role in COVID19 treatment. The trial for remdesivir as a treatment of COVID-19 is underway after the successful treatment of two patients in U.S. [17]. However, it was earlier developed for the Ebola virus to inhibit RNA-dependent RNA polymerase [18]. The clinical trial of antimalarial 
drug hydroxychloroquine for COVID-19 treatment has been completed, and its results are awaited now [19]. It has been proposed that it may work as a prophylactic treatment as it decreases the acidity of endosomes and thus eliminates the virus after ingestion [20]. In addition, it has been proposed that chloroquine and hydroxychloroquine decrease cytokine storms due to massive viral replications [21]. However, based on the effects of previous viruses such as MERS and SARS, alcohol dependence drug (Disulfiram), which inhibits papain-like proteases and anti-HIV drugs (Lopinavir/Ritonavir) that inhibit HIV proteases are being used against this novel coronavirus-2 without confirmed shreds of evidence [22]. One clinical trial using this antiretroviral combination has not shown any significant clinical improvement in China, but another clinical trial is underway in India, whose results are still awaited [23].

Much work is going on worldwide to find novel drugs and vaccines for its treatment [24,25]. Repurposing of FDA-approved drugs is a smart way to seek a solution for development in the SARS-CoV-2 treatment. At present, computer-assisted drug repurposing can play a significant role. This cost-effective approach predicts new biological roles of existing drugs advocating the control of diseases with quick alternative therapies [26]. Similar in silico studies on extracts/bioactive compounds from plants, algae, fungi, etc., are also available [27-36]. Present study intent to identify new dual inhibitors with potential hits against dual SARS-CoV-2 targets, including 3C-like proteases and NSP simultaneously through virtual screening \& molecular docking approach.

\section{Materials and Methods}

\subsection{Target selection \& molecular library preparation.}

The study objective was to design dual inhibitors of SARS-CoV-2. In our study two targets were selected, i.e., 3C-like proteases (3CP) having PDB ID- $6 \mathrm{w} 63$ \& 6lu7 and Nonstructural protein (NSP16) with PDB ID-6w4h. The 3D structure of desired proteins were obtained from the Protein Data Bank (PDB) (https://www.rcsb.org/). The 2D structures of ligands were taken from PubChem open chemistry databases (https://pubchem.ncbi.nlm.nih.gov/). A total of 265 (two hundred and sixty-five) FDA approved drug against infectious disease were selected.

\subsection{Proteins and ligand preparation.}

All the protein structures downloaded from RCSB, Protein Data Bank (PDB) were subjected to preparation using Schrodinger's Protein Preparation Wizard. During processing, the protein was subjected to the addition of the hydrogen atoms, removal of water molecules, creating het states at EpikPh 7 to +-2, the formation of disulfide bonds, and metal atoms formed zero-order bonds. The Schrodinger Prime module was used to add missing atoms, bond orders were conveyed, and methionine was created from selenomethionine [37]. N-terminal hydrogen bond network was optimized to the renovation by overlying hydrogens and energy minimized using OPLS3e force field.

Ligand preparation was done with the Ligprep module of the Schrödinger suite having suitable parameters such as ring conformation, optimization, $2 \mathrm{D}$ to $3 \mathrm{D}$ conversion, determination of promoters, tautomers, and ionization states at $\mathrm{pH} 7.0$; along with partial atomic charges using OPLS3e force field [37]. 


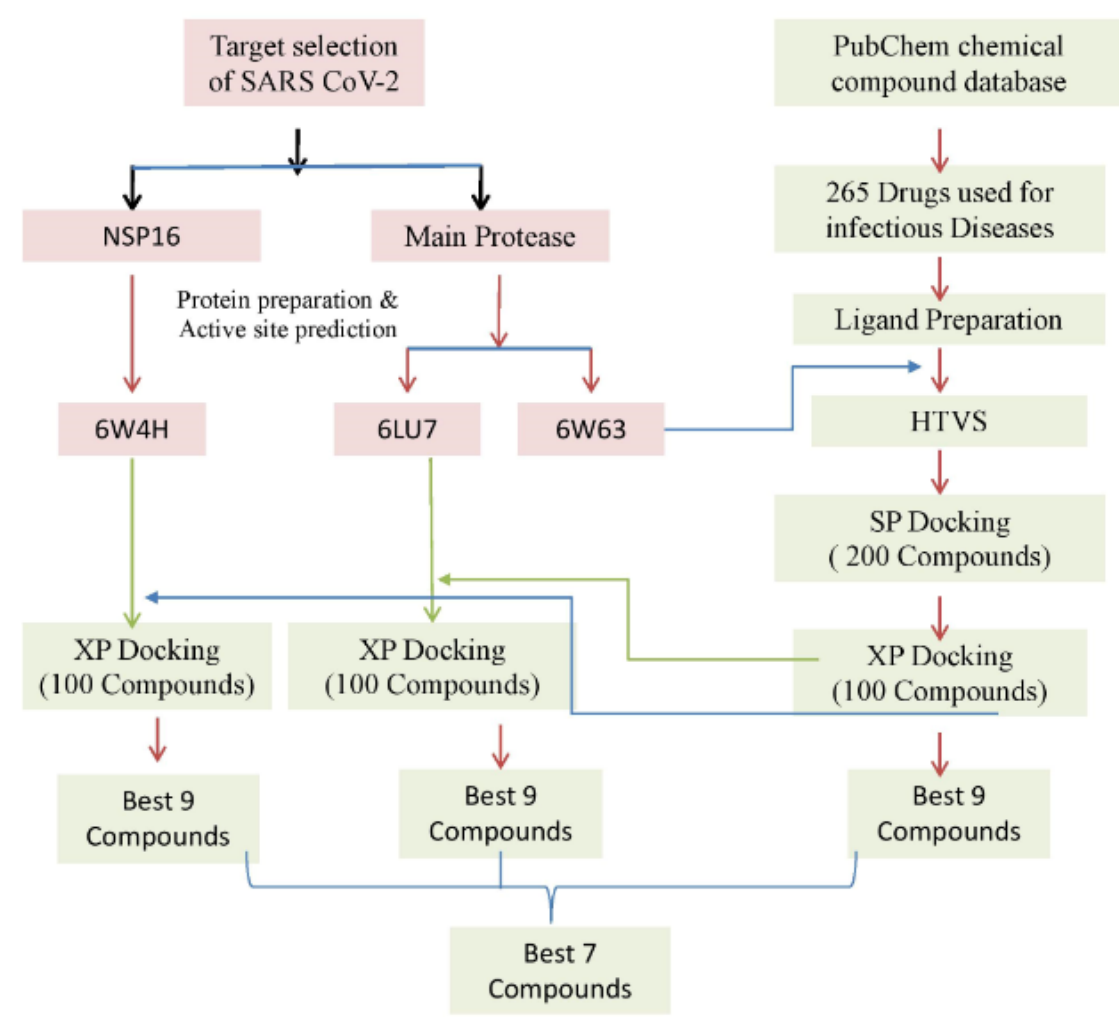

Figure 1. Flow chart showing work plan of this study.

\subsection{Receptor grid generation and active site prediction.}

The native ligand-binding site of the receptor was selected for the generation of the grid box. The receptor grid was generated with the help of the Glide module in the Maestro 12.0 Schrodinger suite by the native ligand of the proteins [38]. The size of the grid box was centroid of native ligands of protein receptors, and the docked ligands were similar in size with respect to the native ligand. Atoms of the protein were fixed within the default radii parameters of van der Waals scaling factor of $1 \AA$ with partial charge cut-off of $0.25 \AA$ using OPLS3e force field[39]. Dimensions of grid box were set up for outer and the internal at $x=20 \AA, y=20 \AA$, $\mathrm{z}=20 \AA$ and $\mathrm{x}=10 \AA, \mathrm{y}=10 \AA, \mathrm{z}=10 \AA$, respectively with the grid space of $1 \AA$ [40].

\subsection{Molecular docking.}

Chemical compounds for High Throughput Virtual Screening (HTVS) against target protein (PDB ID: 6w63) were retrieved from the PubChem database. HTVS, along with flexible docking, was done on Schrodinger's maestro 12.0 model with 265 prepared ligands against receptor grid. After HTVS, 200 ligands were filtered by Standard Precision (SP) using the ligand-docking process. Out of the 200 ligands, 100 ligands with the best conformation having the highest docking score were sorted by Extra Precision (XP), with Flexible docking [41]. These 100 ligands were further docked with two more different target proteins (PDB ID: $6 \mathrm{w} 4 \mathrm{~h}$ and 6lu7). Finally, the best top-nine compounds were selected based on docking scores.

\subsection{Binding free energies calculation using prime MM-GBSA approach.}

Prime MM/GBSA (Molecular Mechanics Generalized Born Surface Area) module of the Schrodinger suite was used to analyze the binding free energies of identified ligand molecules to its receptor complex with the OPLS3e force field [42]. The prime MM/GBSA 
approach is based on the docking complex and is used for calculating the $\Delta \mathrm{G}$ bind of each ligand.

To prioritize the lead inhibitors, MM/GBSA approach was used as a rescoring function. Identified drug molecules were optimized based on binding free energies procured from MM/GBSA calculations and docking scores.

\section{Results and Discussion}

In recent years, drug repurposing has become a blessing for humankind and proves helpful in discovering the new inhibitory potential of FDA-approved drugs against many targets. Here in our present study, we did re-profiling of drugs against SARS-CoV-2. The coronavirus uses distinct domains of spike for its multi-step entry into the cell. First, the virus gets attached to the surface, then receptor engagement occurs, followed by protease processing, and finally, membrane fusion occurs. RBD spike can fold independently and possess complete structural information for binding with the host receptor. Most of the studies revolve around RBD-receptor interactions, but few advocate that host protease plays a vital role in the species barrier. It has been reported that host cell proteases cleave spikes that release fusion peptides, which facilitates the virus's entry. Absence or incompatibility of protease and spike blocks viral entry. Studies suggest that SARS-CoV-2 uses human ACE2 to facilitate human-to-human transmission. Spike and main protease are doorways to form drugs against COVID-19 [43-45]. In CoV-2, the main protease (6w63) is repositioned, structured, and available online. The Discovery of major protease structure in the deadly COVID-19 virus has raised optimistic hope to produce effective drugs against coronavirus.

\subsection{Protein structure reliability.}

The PROCHECK server presents the Ramachandran plot displaying allowed and disallowed regions with regards to the backbone of the dihedrals angle of protein residues. More than $90 \%$ score of the most favored regions ensures a model of good quality. The Ramachandran plot (Figure 2.) of $6 \mathrm{w} 63,6 \mathrm{w} 4 \mathrm{~h}$, and $61 \mathrm{u} 7$ protein structures reveals that $99.7 \%$, $100 \%, 99.6 \%$ of residues fall within the most allowed region in A, B, and C, respectively (Table 1.). Steric interactions are lowest in the red region indicating 3D structure is reliable (A6w63; B- 6w4h; C- 6lu7). This shows minimum steric interactions due to the forbidden psi and the phi angles, thereby advocating good worth of stereochemical quality of 3D Protein structure.

Table 1. Ramachandran Plot statistics showing favored regions in different Covid -19 targets.

\begin{tabular}{l|l|l|l|l|l|l} 
Properties & $\mathbf{6 w 6 3}$ & $\mathbf{6 w 4 H}$ & $\mathbf{6 l U 7}$ \\
\hline & Residues & $\%$ & Residues & $\%$ & Residues & $\%$ \\
\hline The Most favoured regions & 242 & $91.7 \%$ & 324 & $89.3 \%$ & 441 & $90.6 \%$ \\
\hline Additional allowed regions & 19 & $7.2 \%$ & 36 & $9.9 \%$ & 23 & $8.6 \%$ \\
\hline Generously allowed regions & 2 & $0.8 \%$ & 3 & $0.8 \%$ & 1 & $0.4 \%$ \\
\hline Disallowed regions & 1 & $0.4 \%$ & 0 & $0.0 \%$ & 1 & $0.4 \%$ \\
\hline $\begin{array}{l}\text { The End residues } \\
\text { (excluding Glycine and Proline) }\end{array}$ & 2 & & 32 & & 7 & \\
\hline Proline & 13 & & 16 & & 13 & \\
\hline Glycine & 26 & & 4 & & 26 & \\
\hline Total number of residues & 305 & $100 \%$ & 415 & $100 \%$ & 312 & $100 \%$
\end{tabular}



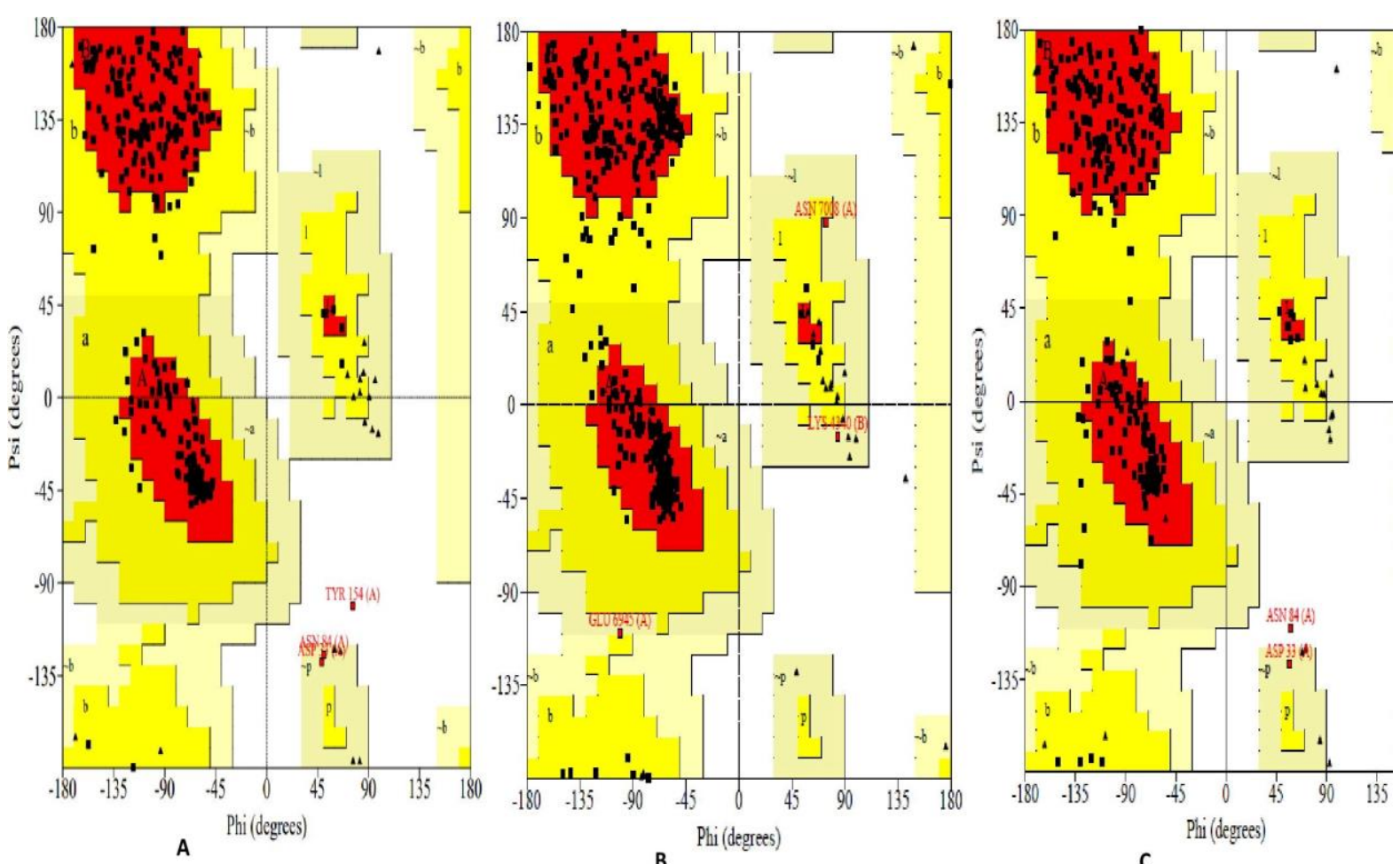

Figure 2. Ramachandran plots of different structures of novel SARS CoV-2 virus proteins describe the stereochemically favored and the disallowed regions of the residues.

\subsection{Binding site prediction and grid generation.}

Identifying residues at the active site and the location of target structures help design the potent drug molecules via protein inhibition at the binding site. Active sites of different protein structures were identified, which showed similarity with native ligand molecules of protein. Site map measures active side residues, docking score \& size for docking study as mentioned in Table 2. During the virtual screening, ligand molecules interact with the binding sites of the protein.

\begin{tabular}{|c|c|c|c|c|c|}
\hline S/No & $\begin{array}{c}\text { PDB } \\
\text { ID }\end{array}$ & DScore & Size & $\begin{array}{c}\text { Site } \\
\text { Score }\end{array}$ & Residues \\
\hline 1. & 6w63 & 1.066 & 120 & 1.02 & $\begin{array}{l}\text { Chain A: 24THR, 25THR, 26THR, 27LEU, 41HIE, 44CYS, 45THR, } \\
\text { 46SER, 49MET, 52PRO, 54TYR, 140PHE, 141LEU, 142ASN, 143GLY, } \\
\text { 144SER, 145CYS, 163HIE, 164HIE, 165MET, 166GLU, 167LEU, } \\
\text { 168PRO, 172HIE, 187ASP, 188ARG, 189GLN, 190THR, 192GLN }\end{array}$ \\
\hline 2. & $6 w 4 h$ & 0.899 & 113 & 1.03 & $\begin{array}{c}\text { Chain A: 6841ASN, 6844LYS, 6845TYR, 6867HIS, 6868PHE, 6869GLY, } \\
\text { 6870ALA, 6871GLY, 6872SER, 6874LYS, 6947PHE, 6968LYS, } \\
\text { 6878PRO, 6879GLY, 6880THR, 6896SER, 6897ASP, 6898LEU, } \\
\text { 6899ASN, 6911GLY, 6912ASP, 6913CYS, 6928ASP, 6929MET, } \\
\text { 6930TYR }\end{array}$ \\
\hline 3. & $61 u 7$ & 1.068 & 132 & 1.01 & $\begin{array}{c}\text { Chain A: 24THR, 25THR, 27LEU, 41HIE, 44CYS, 45THR, 49MET, } \\
\text { 52PRO, 54TYR, 172HIE, 145CYS, 140PHE, 141LEU, 142ASN, 143GLY, } \\
\text { 144SER, 163HIS, 164HIS, 165MET, 166GLU, 167LEU, 168PRO, } \\
\text { 187ASP, 188ARG, 189GLN, 190THR, 192GLN }\end{array}$ \\
\hline
\end{tabular}

3.2.1. Molecular docking and the Ligand optimization using binding free energies [MM-GBSA] and hydrogen bond interactions.

The selection of the most probable drug candidates acquired from virtual screening \& molecular docking of the PubChem dataset was acquired by analyzing scoring functions and 
the binding free energies-MM/GBSA. The top-scored molecules from Tables 3, 4, to 5 were prioritized based on docking score. Further ranking of these molecules was done by rescoring the MM-GBSA function. It indicates the change in the binding free energies of the proteinreceptor complex and confirms docking accuracy and binding affinities.

\subsection{Molecular docking characteristic of $6 w 63,6 w 4 h$, and $6 l u 7$.}

Tables 3, 4, and 5 show the hydrogen bond interactive amino acid residues, prime MM/GBSA free energies, number of hydrogen bonds, and Docking scores of 6w63, 6w4h, and 6lu7, respectively.

Table 3 shows that through B-1 to B-9, the drug molecules interacted with 6 w63 protein structures with a docking score ranging from -7.108 to -8.761 . The binding free energies ( $\Delta$ Gbind) were also in the acceptable range of -46.075 to $-72.832 \mathrm{kcal} / \mathrm{mol}$, and each drug molecule interacted with $6 \mathrm{~W} 63$ protein structures with different amino acid residues through H-bond.

Table 4 depicts that the drug molecules from the serial number C-1 to C- 9 interacted with $6 w 63$ protein structures with docking scores ranging from -7.179 to -13.099 . The binding free energies ( $\Delta$ Gbind) were also in the acceptable range of -39.465 to $-54.867 \mathrm{kcal} / \mathrm{mol}$. Each drug molecule interacted with $6 \mathrm{w} 4 \mathrm{~h}$ protein structures with different amino acid residues through H-bond.

The characteristics from D-1 to D-9 show interaction of drug molecule with 6w63 protein structures with docking scores ranging from -6.034 to -7.765 . The binding free energies ( $\Delta$ Gbind) were also in the acceptable range of -24.045 to $-72.268 \mathrm{kcal} / \mathrm{mol}$, and each drug molecule interacted with $6 \mathrm{lu} 7$ protein structures with different amino acid residues through $\mathrm{H}$ bond (Table 5).

Table 3. Molecular docking results of 6w63 target Protein against top nine lead molecules.

\begin{tabular}{|c|c|c|c|c|c|c|c|}
\hline \multirow[t]{2}{*}{$\mathbf{S} / \mathbf{N}$} & \multirow{2}{*}{$\begin{array}{l}\text { PubChem } \\
\text { ID }\end{array}$} & \multirow{2}{*}{$\begin{array}{l}\text { Name of } \\
\text { Ligand }\end{array}$} & \multirow{2}{*}{$\begin{array}{c}\text { Prime } \\
\text { MM/GBSA }\end{array}$} & \multicolumn{2}{|c|}{ Docking Score } & \multirow{2}{*}{$\begin{array}{c}\text { No. } \\
\text { of } \\
\text { HB }\end{array}$} & \multirow{2}{*}{$\begin{array}{c}\text { H-bond } \\
\text { Interactive Residues }\end{array}$} \\
\hline & & & & Glide & iDock & & \\
\hline B-1 & 446596 & Mupirocin & -53.754 & -8.761 & -6.86 & 5 & $\begin{array}{c}\text { GLY143, ASN142, TYR54 } \\
\text { GLU166, THR190 }\end{array}$ \\
\hline B-2 & 5462355 & Indinavir & -71.378 & -8.562 & -8.56 & 3 & GLN189, GLU166 (2) \\
\hline B-3 & 60934 & Saquinavir & -69.461 & -8.419 & -8.74 & 6 & $\begin{array}{l}\text { GLU166 (2), THR26, } \\
\text { GLN189, CYS145, } \\
\text { GLY143 } \\
\end{array}$ \\
\hline B-4 & 77843966 & Cefiderocol & -69.392 & -7.865 & -7.58 & 6 & $\begin{array}{c}\text { GLN189, THR190, } \\
\text { GLY143, ARG188, THR25, } \\
\text { ASN119 }\end{array}$ \\
\hline B-5 & 441243 & Saquinavir & -51.642 & -7.664 & -8.40 & 6 & $\begin{array}{c}\text { GLU-166 (2), THR26, } \\
\text { GLN189, CYS145, } \\
\text { GLY143 }\end{array}$ \\
\hline B-6 & 392622 & Ritonavir & -72.832 & -7.585 & -7.81 & 2 & ASN142, GLU166 \\
\hline B-7 & 71515458 & Plazomicin & -46.075 & -7.534 & -6.47 & 5 & $\begin{array}{l}\text { PHE140, HIE164, GLU-166 } \\
\text { (3) }\end{array}$ \\
\hline B-8 & 64142 & Nelfinavir & -62.688 & -7.383 & -8.37 & 3 & GLN189, GLU-166 (2) \\
\hline B-9 & 9574768 & $\begin{array}{c}\text { Tenofovir } \\
\text { Alafenamide }\end{array}$ & -57.772 & -7.108 & -7.16 & 4 & $\begin{array}{l}\text { GLN143, HIE164, } \\
\text { GLN192, THR190 }\end{array}$ \\
\hline
\end{tabular}


Table 4. Molecular docking results of $6 \mathrm{w} 4 \mathrm{~h}$ target protein against top nine lead molecules.

\begin{tabular}{|c|c|c|c|c|c|c|c|}
\hline \multirow[t]{2}{*}{$\mathbf{S} / \mathbf{N}$} & \multirow{2}{*}{$\begin{array}{l}\text { PubChem } \\
\text { ID }\end{array}$} & \multirow[t]{2}{*}{ Name of Ligand } & \multirow{2}{*}{$\begin{array}{c}\text { Prime } \\
\text { MM-GBSA }\end{array}$} & \multicolumn{2}{|c|}{ Docking Score } & \multirow{2}{*}{$\begin{array}{c}\text { No } \\
\text { of } \\
\text { HB }\end{array}$} & \multirow{2}{*}{$\begin{array}{c}\text { H-bond } \\
\text { Interactive Residues }\end{array}$} \\
\hline & & & & Glide & iDock & & \\
\hline C-1 & 71515458 & Plazomicin & -47.356 & -13.099 & -6.87 & 8 & $\begin{array}{l}\text { ASA6870, GLY6879, } \\
\text { TYR6930, ASP6912, } \\
\text { GLY6869, ASP6928, } \\
\text { ASP6931, ASP6897 }\end{array}$ \\
\hline $\mathrm{C}-2$ & 77843966 & Cefiderocol & -49.517 & -11.256 & -8.74 & 8 & $\begin{array}{l}\text { ASN6996, ASP6928, } \\
\text { GLY6869, ASP6912 }\end{array}$ \\
\hline $\mathrm{C}-3$ & 135413534 & Valganciclovir & -45.590 & -9.9 & -9.63 & 4 & $\begin{array}{l}\text { ASP6928, TYR6930, } \\
\text { LYS6968, CYS6913 }\end{array}$ \\
\hline C-4 & 23674512 & Ertapenem & -39.465 & -9.377 & -9.23 & 6 & $\begin{array}{l}\text { ASN6841, GLY6871, } \\
\text { ASP6873, CYS6913, } \\
\text { TYR6930, ASP6897 }\end{array}$ \\
\hline C-5 & 392622 & Ritonavir & -42.346 & -7.767 & -8.12 & 2 & ASN6841, CYS6913 \\
\hline C-6 & 6850808 & Caspofungin Acetate & -46.433 & -7.72 & -1.48 & 5 & $\begin{array}{c}\text { ASP6873, TYR6930, } \\
\text { LYS6933, ASN6899, } \\
\text { GLY6869 }\end{array}$ \\
\hline C-7 & 9574768 & TenofovirAlafenamide & -54.867 & -7.686 & -7.41 & 5 & $\begin{array}{c}\text { ASN6841, ASP6928, } \\
\text { LEU6898, CYS6913, } \\
\text { ASP6912 }\end{array}$ \\
\hline C-8 & 63002 & Fexofenadine & -40.822 & -7.62 & -7.53 & 4 & $\begin{array}{l}\text { ASN6841, LYS6844, } \\
\text { TYR6930, ASP6873 }\end{array}$ \\
\hline C-9 & 5462355 & Indinavir & -49.395 & -7.178 & & 4 & $\begin{array}{l}\text { ASN6841, ASP6873, } \\
\text { GLY6871, ASN6899 }\end{array}$ \\
\hline
\end{tabular}

Table 5. Molecular docking results of 6lu7 target protein against Top nine lead molecules.

\begin{tabular}{c|c|c|c|c|c|c} 
S/NO & PubChem & Name of Ligand & Prime & $\begin{array}{c}\text { Docking } \\
\text { Score }\end{array}$ & $\begin{array}{c}\text { No of } \\
\text { HB }\end{array}$ & H-bond \\
\hline D-1 & 441243 & Saquinavir & -72.268 & -7.765 & 7 & $\begin{array}{c}\text { HIE41, HIS163, HIS164, } \\
\text { GLU166(4) }\end{array}$ \\
\hline D-2 & 5462355 & Indinavir & -54.617 & -7.564 & 5 & GLN189(2), GLU166(3) \\
\hline D-3 & 71515458 & Plazomicin & -46.851 & -7.452 & 8 & $\begin{array}{c}\text { HIS164, GLU166(3), } \\
\text { LEU167, ASN142, } \\
\text { GLN189(2) }\end{array}$ \\
\hline D-4 & 64142 & Nelfinavir & -54.923 & -7.323 & 4 & GLY143, GLU166(3) \\
\hline D-5 & 392622 & Ritonavir & -24.045 & -6.499 & 3 & HIE41, HIS164, GLU166 \\
\hline D-6 & 9574768 & TenofovirAlafenamide & -53.844 & -6.481 & 2 & HIS164, THR190 \\
\hline D-7 & 45375808 & Sofosbuvir & -50.692 & -6.471 & 3 & CYS145, HIS165, THR190 \\
\hline D-8 & 6256 & Trifluridine & -29.459 & -6.401 & 1 & THR190 \\
\hline D-9 & 54682461 & Tipranavir & -55.419 & -6.034 & 1 & GLU166
\end{tabular}

3.4. Potential ligands against all the targets.

Out of 27 drugs ( 9 for each target), the best seven drugs were sorted based on the number of hydrogen bonds, ligand-binding affinity (free energy values), interactive residues and docking scores. 


\section{Docking Scores of best drugs against $6 w 63,6 w 4 h$ and $6 l u 7$}

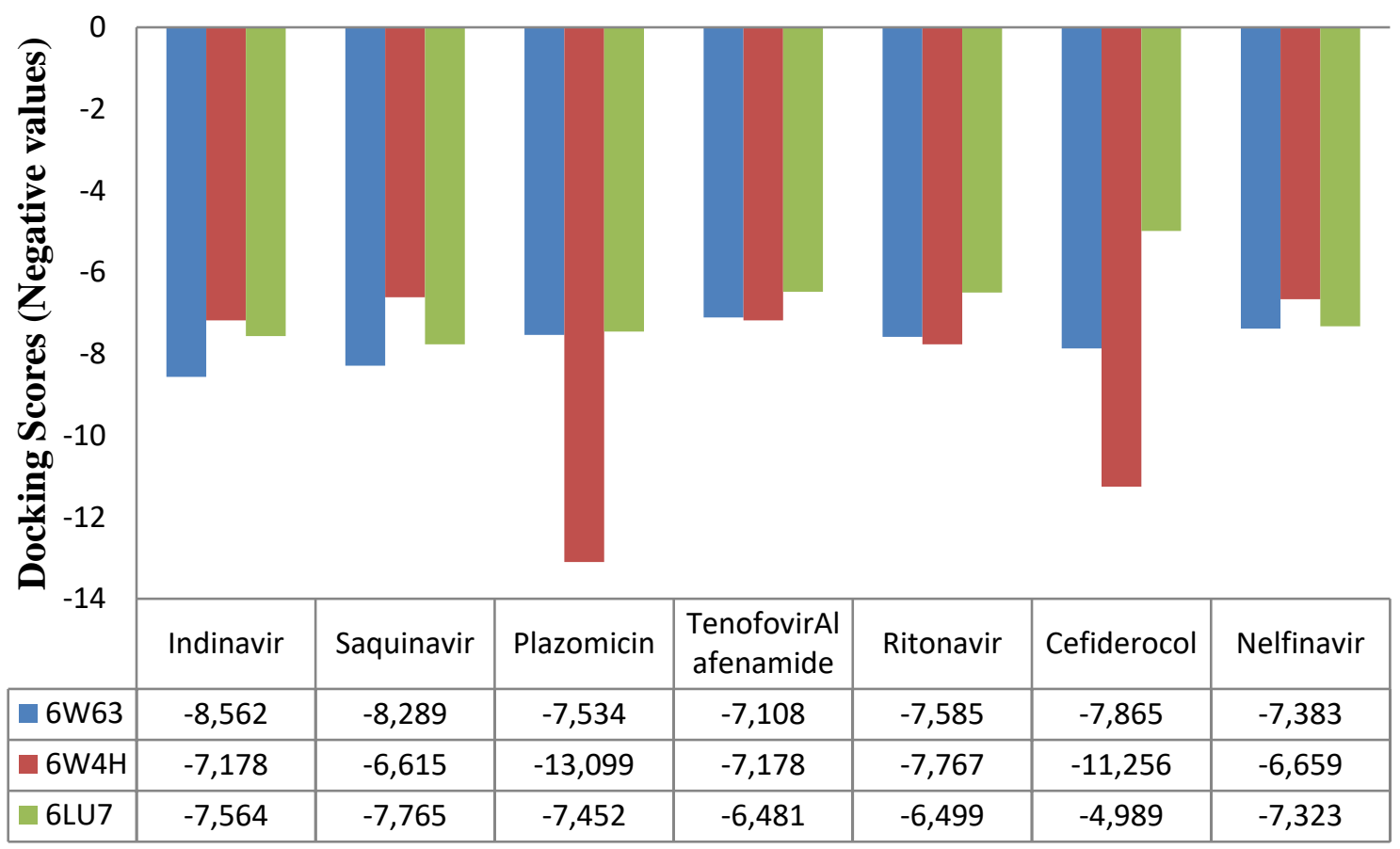

Figure 3. Comparative-docking scores of best seven drugs against different targets of SARS CoV-2.

$\mathrm{MM} / \mathrm{GBSA}$ values of best drugs against $6 \mathrm{~W} 63,6 \mathrm{~W} 4 \mathrm{H}$ and $6 \mathrm{LU7}$

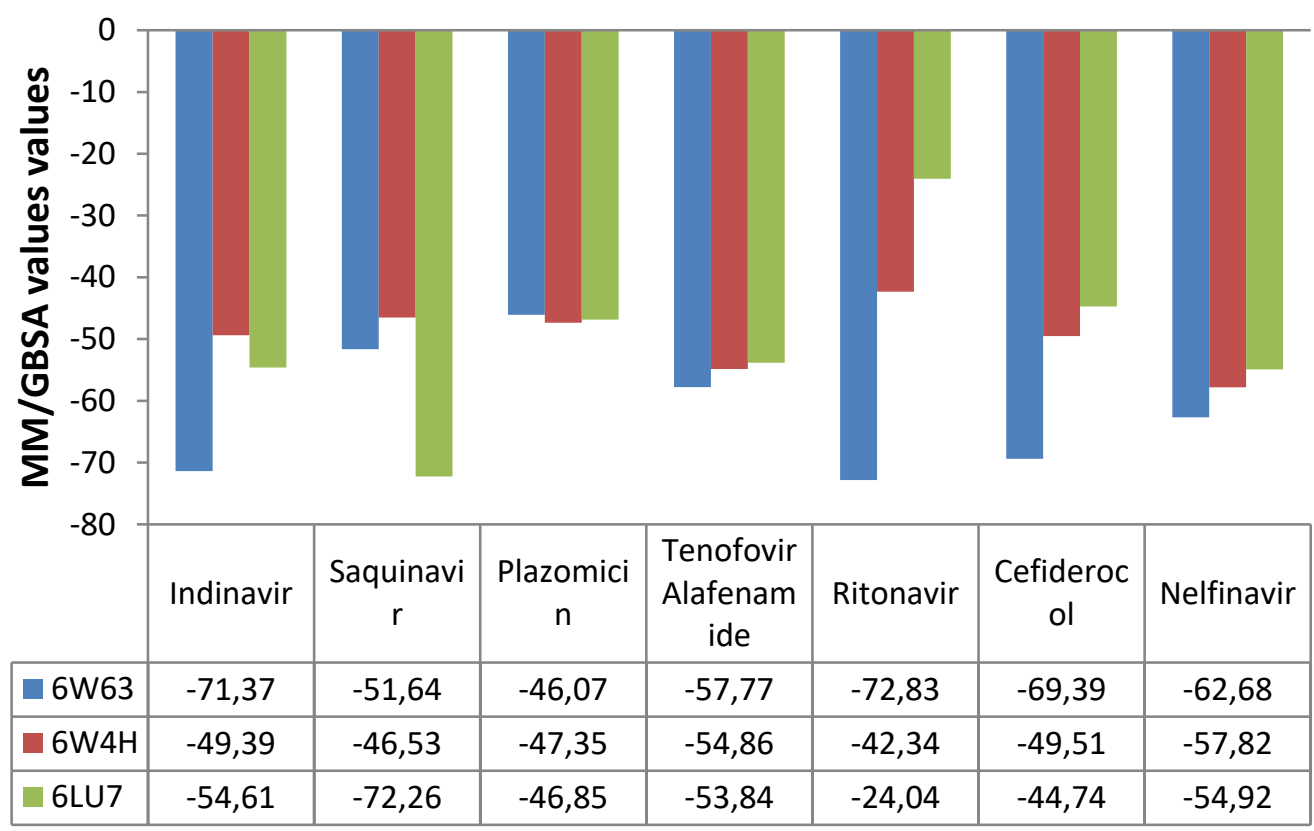

Figure 4. Comparative MM-GBSA values of the best seven drugs against different targets of CoV-2.

These seven drug molecules showed the best docking scores and good interaction with all the targets. These seven drugs depict reliable interaction with the main protease also. Comparison of the docking scores and the MM/GBSA values of the best seven drug molecules presented in Figures 3 and 4 depicts that Indinavir drug showed the highest docking and $\mathrm{MM} / \mathrm{GBSA}$ values in common all three receptors. 
The number of hydrogen bonds and the residues act as driving forces for the precise binding of ligand to its receptor.

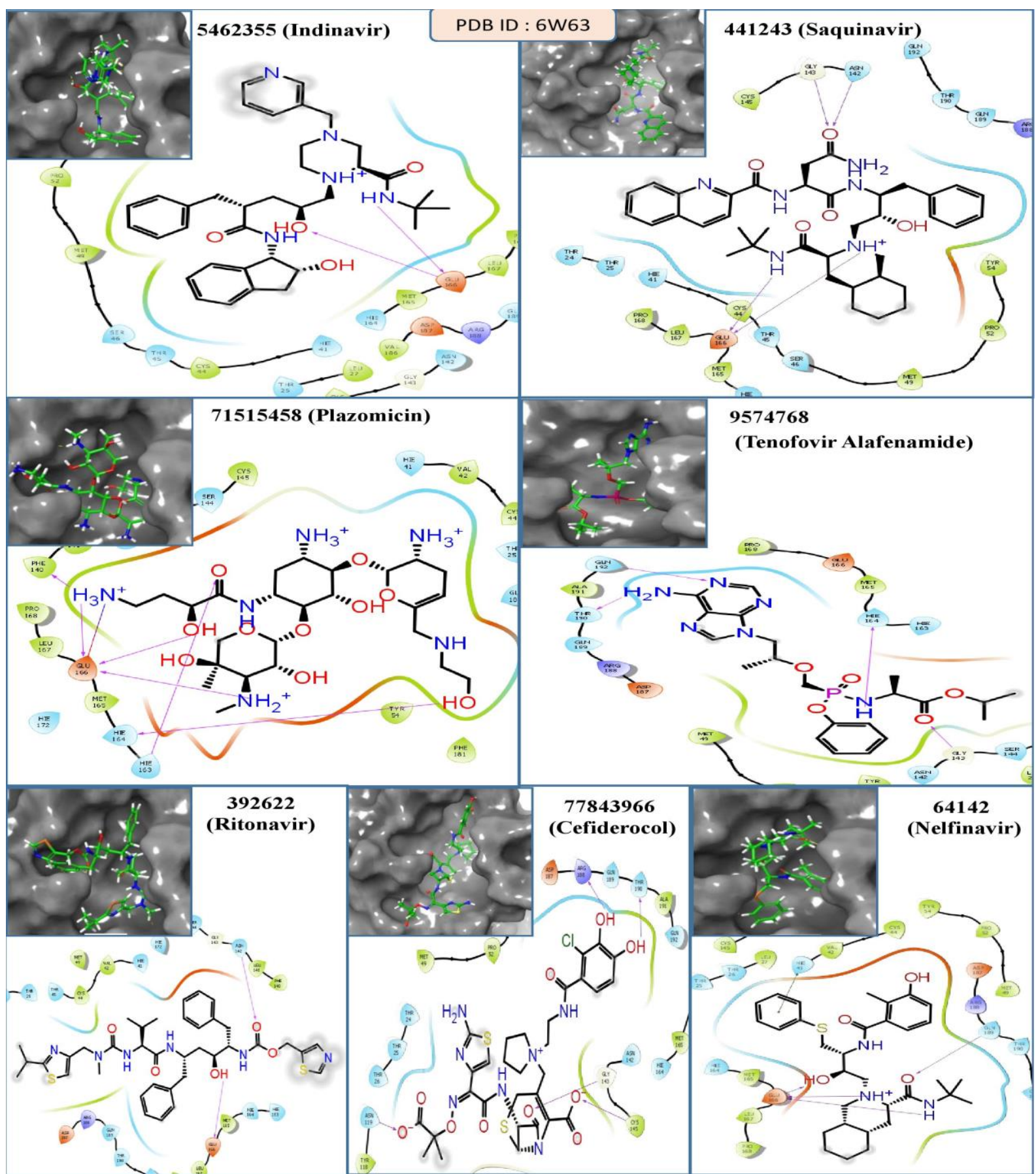

Figure 5. Binding mode and the chemical interactions of lead molecules along with residues at the active site of 6w63 are obtained from Schrodinger software.

The ligand's chemical interaction and potential binding to its receptor are pictorially presented for all three targets (Figures 5,6,7). Ligand molecules Indinavir and Nelfinavir form 3 H-bonds, Saquinavir and Cefiderocol form $6 \mathrm{H}$ - bonds, whereas Plazomicin, Tenofoviralafenamide, and Ritonavir form 5, 4, $2 \mathrm{H}$ - bonds respectively with target 6w63. Ligand molecules Saquinavir and Tenofoviralafenamide form $5 \mathrm{H}$-bonds, Plazomicin and Cefiderocol form $8 \mathrm{H}$-bonds, whereas Indinavir, Ritonavir, and Nelafinavir form 4, 2, $3 \mathrm{H}$ bonds respectively with target $6 \mathrm{w} 4 \mathrm{~h}$. However, all 7 best ligand molecules form a different number of $\mathrm{H}$ - bonds with target 6lu7. Such as Indinavir, Saquinavir, Plazomicin, 
Tenofoviralafenamide, Ritonavir, Cefiderocol, and Nelfinavir forms 5,7,8,2,3,6,4 H- bonds, respectively.

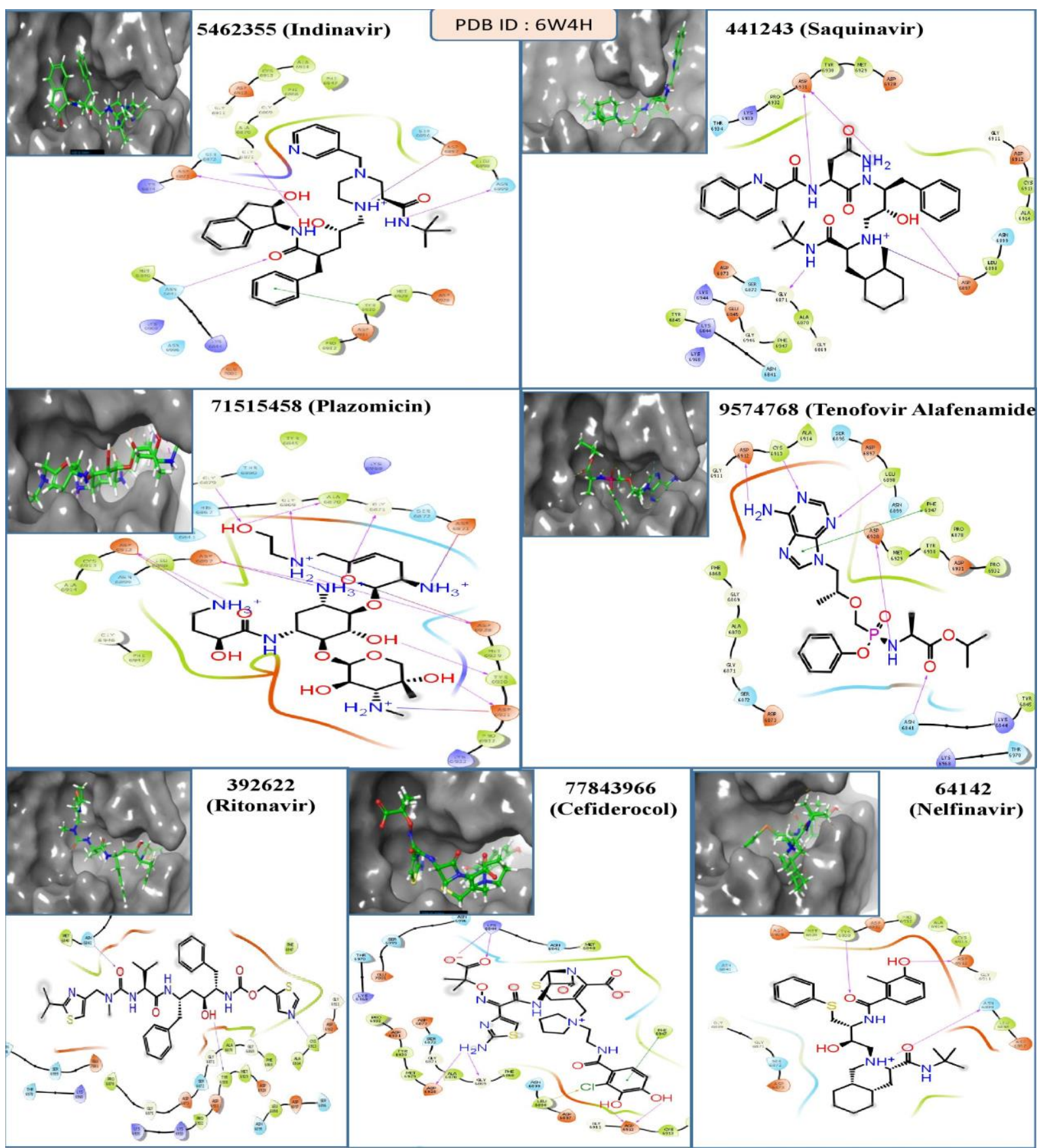

Figure 6. Binding mode and the chemical interactions of lead molecules with residues at the active site of $6 \mathrm{w} 4 \mathrm{~h}$ are depicted through Schrodinger software.

\subsection{Biological activity of the best drugs.}

Classification of these potential COVID-19 drugs shows that the best five are reported to target HIV-proteases and anti-HIV drugs, i.e., Saquinavir, Indinavir TenofovirAlafenamide, Ritonavir, and Nelfinavir mesylate. The other two ligands are antibacterial drugs that are, Plazomicin and Cefiderocol (Table 6.)[46]. These ligands have shown a good docking score and reliable binding energy for all the Covid-19 targets. The use of these ligands against Covid19 may inhibit 3C-like proteinase as well as Non-structural protein 10 (NSP16), maybe a 
beginning to form novel drugs against the coronavirus, which is required to save the human race on earth.

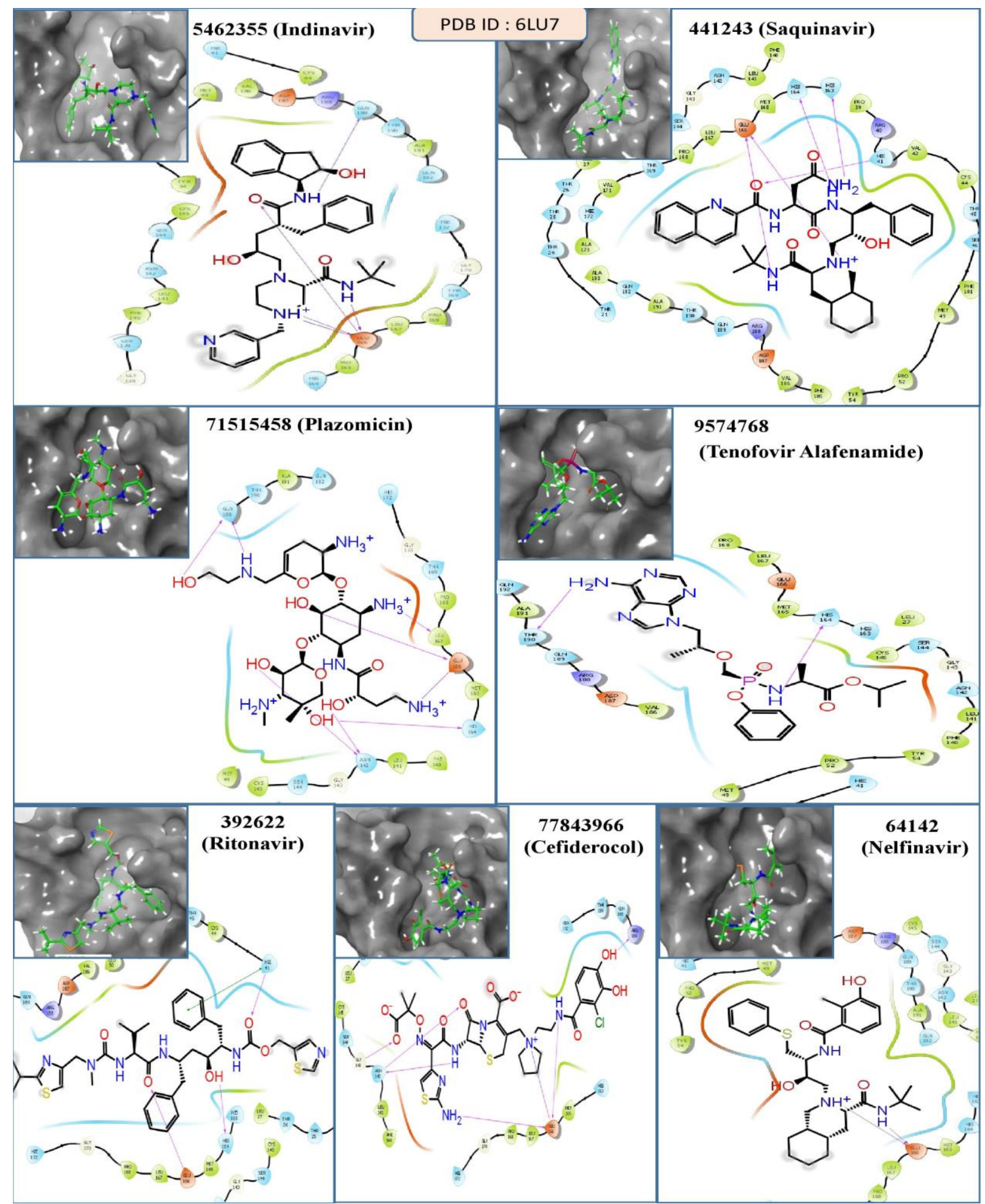

Figure 7. Binding mode and chemical interactions of best lead molecules with residues at active site of 6lu7 are depicted through Schrodinger software.

Table 6. Potential seven FDA-approved drugs and their biological activities.

\begin{tabular}{l|l|l|l} 
Drug & Name of drug & Indication & Mechanism of Action \\
\hline $\mathbf{4 4 1 2 4 3}$ & Saquinavir & $\begin{array}{l}\text { Human Immunodeficiency } \\
\text { Virus type-1 (HIV-1) infection. }\end{array}$ & $\begin{array}{l}\text { Inhibits the HIV viral proteinase enzyme } \\
\text { https://www.drugbank.ca/drugs/DB01232 }\end{array}$ \\
\hline $\mathbf{5 4 6 2 3 5 5}$ & Indinavir & $\begin{array}{l}\text { Antiretroviral drugs are used } \\
\text { for the treatment of HIV } \\
\text { infection. }\end{array}$ & $\begin{array}{l}\text { Inhibits HIV viral protease enzyme } \\
\text { https://www.drugbank.ca/drugs/DB00224 }\end{array}$
\end{tabular}




\begin{tabular}{l|l|l|l}
\hline Drug & Name of drug & Indication & Mechanism of Action \\
\hline $\mathbf{9 5 7 4 7 6 8}$ & $\begin{array}{l}\text { Tenofovir } \\
\text { Alafenamide }\end{array}$ & $\begin{array}{l}\text { Indicated for the treatment of } \\
\text { chronic hepatitis B infection. }\end{array}$ & $\begin{array}{l}\text { Inhibition of viral polymerase, causing chain termination } \\
\text { and the inhibition of viral synthesis } \\
\text { https://www.drugbank.ca/drugs/DB09299 }\end{array}$ \\
\hline $\mathbf{7 1 5 1 5 4 5 8}$ & Plazomicin & $\begin{array}{l}\text { Complicate Urinary Tract } \\
\text { Infections (cUTI), including } \\
\text { pyelonephritis. }\end{array}$ & $\begin{array}{l}\text { Bactericidal action against susceptible bacteria by } \\
\text { binding to bacterial 30S ribosomal subunit } \\
\text { https://www.drugbank.ca/drugs/DB12615 }\end{array}$ \\
\hline $\mathbf{3 9 2 6 2 2}$ & Ritonavir & Treatment of HIV-1 infection. & $\begin{array}{l}\text { Inhibits the HIV viral proteinase enzyme. } \\
\text { https://www.drugbank.ca/drugs/DB00503 }\end{array}$ \\
\hline $\mathbf{7 7 8 4 3 9 6 6}$ & Cefiderocol & $\begin{array}{l}\text { Complicated urinary tract } \\
\text { infections with or without } \\
\text { pyelonephritis. }\end{array}$ & $\begin{array}{l}\text { Inhibiting PBPs, preventing cell wall synthesis and } \\
\text { ultimately causing the death of the bacterial cell. } \\
\text { https://www.drugbank.ca/drugs/DB14879 }\end{array}$ \\
\hline $\mathbf{6 4 1 4 2}$ & $\begin{array}{l}\text { Nelfinavir } \\
\text { mesylate }\end{array}$ & $\begin{array}{l}\text { HIV-1 protease inhibitor. } \\
\text { https://www.drugbank.ca/salts/DBSALT000885 }\end{array}$
\end{tabular}

\section{Conclusions}

Computer-assisted functional and the structural insights into FDA-approved drug for the infectious diseases group in PubChem database has shown good binding affinities, docking scores and hits for all CoV-2 targets, i.e., 6w63, 6lu7, and 6w4h. Anti-HIV and anti- HBV drugs like Saquinavir, Indinavir, TenofovirAlafenamide, Ritonavir, and Nelfinavir mesylate interacted with main proteases and Non-structural proteins of SARS CoV-2. As per our study, these drugs, along with two antibacterial drugs (Cefiderocol and Plazomicin), have shown great dual inhibitor potential against the targets of Covid-19 (main protease and NSP). Hence, our study suggests that these ligands can be new drug prospects for treating COVID-19 as dual inhibitors. Individually a combination of these ligands can be predicted for the development of novel drugs against $\mathrm{CoV}-2$.

\section{Funding}

There was no funding from any external agency for this piece of work.

\section{Acknowledgment}

The author is thankful to Dr. Prajwal Nandekar, Mr. Vinod Devaraji, and Ms. Shelvia Malik of Schrodinger, Bengaluru, India, for their kind help.

\section{Conflicts of Interest}

The author declares no conflict of interest.

\section{References}

1. Yadav, R.; Chaudhary, J. K.; Jain, N.; Chaudhary, P. K.; Khanra, S.; Dhamija, P.; Sharma, A.; Kumar, A.; Handu, S. Role of Structural and Non-Structural Proteins and Therapeutic Targets of SARS-CoV-2 for COVID-19. Cells 2021, 10, 821, https://doi.org/10.3390/cells10040821.

2. Lu, R.; Zhao, X.; Li, J.; Niu, P.; Yang, B.; Wu, H.; Tan, W. Genomic characterisation and epidemiology of 2019 novel coronavirus: implications for virus origins and receptor binding.Lancet 2020, 395, 565-574, https://doi.org/10.1016/S0140-6736(20)30251-8.

3. Cucinotta, D.; Vanelli, M. WHO declares COVID-19 a pandemic. Acta Bio Medica 2020, 91, 157, https://doi.org/10.23750/abm.v91i1.9397.

4. Kang, S.; Peng, W.; Zhu, Y.; Lu, S.; Zhou, M.; Lin, W.; Wu, W.; Huang, S.; Jiang, L.; Luo, X.; Deng, M. Recent progress in understanding 2019 novel coronavirus (SARS-CoV-2) associated with human respiratory 
disease: detection, mechanisms and treatment. Int. J. Antimicrob. Agents 2020,55, 105950, https://doi.org/10.1016/j.ijantimicag.2020.105950.

5. Wu, F.; Zhao, S.; Yu, B.; Chen, Y. M.; Wang, W.; Song, Z. G.; Zhang, Y. Z. A new coronavirus associated with human respiratory disease in China. Nature 2020, 579, 265-269, https://doi.org/10.1038/s41586-0202008-3.

6. Chan, J.F.W.; Kok, K.H., Zhu, Z.; Chu, H.; To, K.K.W.; Yuan, S.; Yuen, K.Y. Genomic characterization of the 2019 novel human-pathogenic coronavirus isolated from a patient with atypical pneumonia after visiting Wuhan. Emerg Microbes Infects 2020, 9, 221-236, https://doi.org/10.1080/22221751.2020.1719902.

7. Gralinski, L.E.; Menachery, V.D. Return of the Coronavirus: 2019-nCoV. Viruses 2020, 12, 135, https://doi.org/10.3390/v12020135.

8. Schoeman, D.; Fielding, B.C. Coronavirus envelope protein: current knowledge. Virol. J. 2019, 16, 1-22, https://doi.org/10.1186/s12985-019-1182-0.

9. UniProt. Available from: https://covid-19.uniprot.org/uniprotkb/P0DTD1.

10. Liu, Y.; Chan, W.K.; Wang, Z.; Hur, J.; Xie, J.; Yu, H.; He, Y. Ontological and bioinformatic analysis of anti-coronavirus drugs and their Implication for drug repurposing against COVID-19. 2020, https://doi.org/10.20944/preprints202003.0413.v1.

11. Dong, L.; Hu, S.; Gao, J. Discovering drugs to treat coronavirus disease 2019 (COVID-19). Drug Discov Ther 2020, 14, 58-60, https://doi.org/10.5582/ddt.2020.01012.

12. Coronavirus (COVID-19) events as they happen. Available online: https://www.who.int/emergencies/diseases/novel-coronavirus-2019/events-as-they-happen.

13. Chen, C.; Qi, F.; Shi, K.; Li, Y.; Li, J.; Chen, Y.; Pan, J.; Zhou, T.; Lin, X.; Zhang, J.; Luo, Y.; Li, X.; Xia, J. Thalidomide Combined with Low-dose Glucocorticoid in the Treatment of COVID-19 Pneumonia. Preprints 2020, 2020020395

14. Richardson, P.; Griffin, I.; Tucker, C.; Smith, D.; Oechsle, O.; Phelan, A.; Rawling, M.; Savory, E.; Stebbing, J. Baricitinib as potential treatment for 2019-nCoV acute respiratory disease. Lancet 2020, 395, e30, https://doi.org/10.1016/S0140-6736(20)30304-4.

15. Shen, C.; Wang, Z.; Zhao, F.,et al. Treatment of 5 critically ill patients with COVID-19 with convalescent plasma. Jama 2020, 323, 1582-1589, https://doi.org/10.1001/jama.2020.4783.

16. Chen, L.; Xiong, J.; Bao, L.; Shi, Y. Convalescent plasma as a potential therapy for COVID-19.The Lancet Infect Dis 2020, 20, 398-400, https://doi.org/10.1016/S1473-3099(20)30141-9.

17. Bhatnagar, T.; Murhekar, M. V.; Soneja, M.; Gupta, N.; Giri, S.; Wig, N.; Gangakhedkar, R. Lopinavir/ritonavir combination therapy amongst symptomatic coronavirus disease 2019 patients in India: Protocol for restricted public health emergency use. Indian J. of Med. Res. 2020, 151, 184, https://doi.org/10.4103/ijmr.IJMR_502_20.

18. Gordon, C. J.; Tchesnokov, E. P.; Feng, J. Y.; Porter, D. P.; Götte, M. The antiviral compound remdesivir potently inhibits RNA-dependent RNA polymerase from Middle East respiratory syndrome coronavirus. $J$. Biol. Chem. 2020, 295, 4773-4779, https://doi.org/10.1074/jbc.AC120.013056.

19. Efficacy and Safety of Hydroxychloroquine and Azithromycin for the Treatment of Ambulatory Patients With Mild COVID-19. Available online: https://clinicaltrials.gov/ct2/show/NCT04348474.

20. Bevan, A.P.; Krook, A.; Tikerpae, J.; Seabright, P.J.; Siddle, K.; Smith, G.D. Chloroquine extends the lifetime of the activated insulin receptor complex in endosomes. J. Biol. Chem. 1997, 272, 26833-26840, https://doi.org/10.1074/jbc.272.43.26833.

21. Mehta, P.; McAuley, D.F.; Brown, M.; Sanchez, E.; Tattersall, R.S.; Manson, J.J. COVID-19: consider cytokine storm syndromes and immunosuppression. The lancet 2020, 395, 1033-1034, https://doi.org/10.1016/S0140-6736(20)30628-0.

22. Lin, M.H.; Moses, D.C.; Hsieh, C.H.; Cheng, S.C.; Chen, Y.H.; Sun, C.Y.; Chou, C.Y. Disulfiram can inhibit MERS and SARS coronavirus papain-like proteases via different modes. Antivir. Res. 2018, 150, 155163, https://doi.org/10.1016/j.antiviral.2017.12.015.

23. Bhatnagar, T.; Murhekar, M. V.; Soneja, M.; Gupta, N.; Giri, S.; Wig, N.; Gangakhedkar, R. Lopinavir/ritonavir combination therapy amongst symptomatic coronavirus disease 2019 patients in India: Protocol for restricted public health emergency use. Indian J. of Med. Res. 2020, 151, 184, https://doi.org/10.4103/ijmr.IJMR_502_20.

24. Herst, C.V.; Burkholz, S.; Sidney, J.; Sette, A.; Harris, P. E.; Massey, S.; Brasel, T.; Cunha-Neto, E.;Rosa, D.S.; Chao, W.C.H.; Carback, R.; Hodge, T.; Wang, L.; Ciotlos, S.; Lloyd, P.; Rubsamen, R. An effective CTL peptide vaccine for Ebola Zaire Based on Survivors' CD8+ targeting of a particular nucleocapsid protein 
epitope with potential implications for COVID-19 vaccine design. Vaccine 2020,38, 4464-4475, https://doi.org/10.1016/j.vaccine.2020.04.034.

25. Yamey, G.; Schäferhoff, M.; Hatchett, R.; Pate, M.; Zhao, F.; McDade, K. K. Ensuring global access to COVID-19 vaccines.The Lancet, 2020,395,1405-1406, https://doi.org/10.1016/S0140-6736(20)30763-7

26. Li, Y.Y.; Jones, S.J. Drug repositioning for personalized medicine. Genome Med. 2012, 4, 1-14, https://doi.org/10.1186/gm326.

27. Rangsinth, P.; Sillapachaiyaporn, C.; Nilkhet, S.; Tencomnao, T.; Ung, A. T.; Chuchawankul, S. Mushroomderived bioactive compounds potentially serve as the inhibitors of SARS-CoV-2 main protease: An in silico approach. J Tradit l and Complement Med 2021, 11, 158-172, https://doi.org/10.1016/j.jtcme.2020.12.002.

28. Singh, R.; Gautam, A.; Chandel, S.; Sharma, V.; Ghosh, A.; Dey, D.; Roy, S.; Ravichandiran, V.; Ghosh, D. Computational screening of FDA approved drugs of fungal origin that may interfere with SARS-CoV-2 spike protein activation, viral RNA replication, and post-translational modification: a multiple target approach. In silico Pharmacol 2021, 9, 1-16, https://doi.org/10.1007/s40203-021-00089-8

29. Arunkumar, M.; Gunaseelan, S.; Kubendran Aravind; M., Mohankumar, V.; Anupam, P.; Harikrishnan, M.; Siva, A.; Ashokkumar, B.; Varalakshmi, P. Marine algal antagonists targeting 3CL protease and spike glycoprotein of SARS-CoV-2: a computational approach for anti-COVID-19 drug discovery. J Biomol Struct Dyn 2021, 1-28, https://doi.org/10.1080/07391102.2021.1921032.

30. Kumar, V.; Parate, S.; Yoon, S.; Lee, G.; Lee, K.W. Computational Simulations Identified Marine-Derived Natural Bioactive Compounds as Replication Inhibitors of SARS-CoV-2. Front in Microbiol 2021, 12, https://dx.doi.org/10.3389\%2Ffmicb.2021.647295.

31. Ibrahim, M.A.; Abdelrahman, A.H.; Mohamed, T.A.; Atia, M.A.; Al-Hammady, M.A.; Abdeljawaad, K.A.; Elkady, E.M.; Moustafa, M.F.; Alrumaihi, F,; Allemailem, K.S.; El-Seedi, H.; Paré, P.W.; Efferth, T.; Hegazy, M.E.F. In Silico Mining of Terpenes from Red-Sea Invertebrates for SARS-CoV-2 Main Protease (Mpro) Inhibitors. Molecules 2021, 26, 2082, https://doi.org/10.3390/molecules26072082.

32. Kaur, H.; Shekhar, N.; Sharma, S.; Sarma, P.; Prakash, A.; Medhi, B. Ivermectin as a potential drug for treatment of COVID-19: an in-sync review with clinical and computational attributes. Pharmacol Rep 2021, 1-14, https://doi.org/10.1007/s43440-020-00195-y.

33. Verma, A.K.; Kumar, V.; Singh, S.; Goswami, B.C.; Camps, I.; Sekar, A.; Yoon, S.; Lee, K.W. Repurposing potential of Ayurvedic medicinal plants derived active principles against SARS-CoV-2 associated target proteins revealed by molecular docking, molecular dynamics and MM-PBSA studies. Biomed. Pharmacother. 2021, 137, 111356, https://doi.org/10.1016/j.biopha.2021.111356.

34. Enmozhi, S.K.; Raja, K.; Sebastine, I.; Joseph, J. Andrographolide as a potential inhibitor of SARS-CoV-2 main protease: An in silico approach. J. Biomol. Struct. Dyn. 2020, 1-7, https://doi.org/10.1080/07391102.2020.1760136.

35. Maffucci, I.; Contini, A. In Silico Drug Repurposing for SARS-CoV-2 Main Proteinase and Spike Proteins. $J$ Proteome Res 2020, 19, 4637-4648, https://doi.org/10.1021/acs.jproteome.0c00383.

36. Indu, P.; Rameshkumar, M.R.; Arunagirinathan, N.; Al-Dhabi, N.A.; Arasu, M.V.; Ignacimuthu, S. Raltegravir, Indinavir, Tipranavir, Dolutegravir, and Etravirine against main protease and RNA-dependent RNA polymerase of SARS-CoV-2: A molecular docking and drug repurposing approach. J. Infect. Public Health 2020, 13, 1856-1861, https://doi.org/10.1016/j.jiph.2020.10.015.

37. Sastry, G.M.; Adzhigirey, M.; Day, T.; Annabhimoju, R.; Sherman, W. Protein and ligand preparation: parameters, protocols, and influence on virtual screening enrichments. J. Comput. Aided Mol. Des. 2013, 27, 221-234, https://doi.org/10.1007/s10822-013-9644-8.

38. Halgren, T.A.; Murphy, R.B.; Friesner, R.A.; Beard, H.S.; Frye, L.L.; Pollard, W.T.; Banks, J.L. Glide: a new approach for rapid, accurate docking and scoring. 2. Enrichment factors in database screening. J. Med. Chem. 2004, 47, 1750-1759, https://doi.org/10.1021/jm030644s.

39. Lanka, G.; Bathula, R.; Dasari, M.; Nakkala, S.; Bhargavi, M.; Somadi, G.; Potlapally, S.R. Structure-based identification of potential novel inhibitors targeting FAM3B (PANDER) causing type 2 diabetes mellitus through virtual screening. J. Recept. Signal Transduct. 2019, 39, 253-263, https://doi.org/10.1021/jm030644s.

40. Halgren, T.A. Identifying and characterizing binding sites and assessing druggability. J. Chem. Inf. Model. 2009, 49, 377-389, https://doi.org/10.1021/ci800324m

41. Friesner, R.A.; Murphy, R.B.; Repasky, M.P.; Frye, L.L.; Greenwood, J.R.; Halgren, T.A.; Sanschagrin, P.C.; Mainz, D.T. Extra precision glide: Docking and scoring incorporating a model of hydrophobic enclosure for protein-ligand complexes. J. Med. Chem. 2006, 49, 6177-6196, https://doi.org/10.1021/jm051256o. 
42. Genheden, S.;Ryde, U. The MM/PBSA and MM/GBSA methods to estimate ligand-binding affinities. Expert Opin. Drug Discov. 2015, 10, 449-461, https://doi.org/10.1517/17460441.2015.1032936.

43. Yadav, R.; Imran, M.; Dhamija, P.; Chaurasia, D.K.; Handu, S. Virtual screening, ADMET prediction and dynamics simulation of potential compounds targeting the main protease of SARS-CoV-2. J. Biomol. Struct. Dyn. 2020, 1-16, https://doi.org/10.1080/07391102.2020.1796812

44. Yadav, R.; Parihar, R.D.; Dhiman, U.; Dhamija, P.; Upadhyay, S.K.; Imran, M.; Behera, S.K.; Prasad, T.S.K. Docking of fda approved drugs targeting nsp-16, n-protein and main protease of sars-cov-2 as dual inhibitors. Biointerface Res. Appl. Chem. 2020, 11, https://doi.org/10.33263/BRIAC113.98489861.

45. de Oliveira, O.V.; Rocha, G. B.; Paluch, A.S.; Costa, L.T. Repurposing approved drugs as inhibitors of SARS-CoV-2 S-protein from molecular modeling and virtual screening. J. Biomol. Struct. Dyn. 2020, 1-10, https://doi.org/10.1080/07391102.2020.1772885.

46. DRUGBANK online. https://go.drugbank.com/. (05 May 2021) 